\title{
Peran Komitmen Organisasional Dalam Pengaruh Kepuasan Kerja Dan Kualitas Kehidupan Kerja Terhadap Kinerja Karyawan PT. Ramayana Lestari Sentosa, Tbk Cabang Sleman
}

\author{
${ }^{1}$ Ignatius Soni Kurniawan, ${ }^{2}$ Koni Awes Nurlita
}

Universitas Sarjanawiyata Tamansiswa, Yogyakarta, Indonesia.

Email: ${ }^{1}$ soni_kurniawan@ustjogja.ac.id, $2{ }^{2}$ koniawesnurlita@gmail.com

(Diterima: Feb 2021; Direvisi: Maret 2021; Dipublikasikan: Mei 2021)

\begin{abstract}
ABSTRAK
Penelitian bertujuan untuk mengetahui pengaruh kepuasan kerja dan kualitas kehidupan kerja terhadap kinerja karyawan dengan komitmen organisasional sebagai variabel pemediasi. Penelitian dilakukan terhadap 80 karyawan PT. Ramayana Lestari Sentosa, Tbk Cabang Sleman. Pengumpulan data dilakukan melalui survei dengan kuesioner yang didistribusikan secara offline. Teknik pengambilan sampling dengan sampel jenuh. Jenis penelitian ini bersifat deskriptif kuantitatif. Metode analisis data dengan uji instrumen, uji asumsi klasik, uji hipotesis, dan sobel test. Temuan menunjukkan bahwa kepuasan kerja tidak berpengaruh secara langsung terhadap kinerja karyawan yang dimediasi oleh komitmen organisasional. Ditemukan juga kualitas kehidupan kerja berpengaruh langsung terhadap kinerja dengan dimediasi oleh komitmen organisasional.
\end{abstract}

Kata Kunci : Kepuasan, Kualitas, Komitmen Organisasional, Kinerja. 


\section{PENDAHULUAN}

Pada era industri saat ini kemajuan manajemen pada bidang sumber daya manusia semakin berkembang. Upaya mencapai pertumbuhan industri yang memuaskan salah satunya didukung oleh pencapaian kepuasan kerja pada pegawai. Mencapai sebuah kepuasan kerja sangat penting bagi pegawai maupun perusahaan. Hal tersebut penting diperhatikan bagi sebuah perusahaan untuk membawa perubahan dan hasil yang baik berkaitan dengan masalah sumber daya manusia(SDM). Penting guna perkembangan dan kemajuan perusahaan. Manajer perlu memberikan perhatian khusus kepada SDM dalam sebuah perusahaan sehingga pegawai mampu bertahan dan meningkatkan kinerjanya dengan optimal. Bagi setiap pegawai bekerja dalam sebuah perusahaan sejak diterima sampai memasuki masa pensiun pastinya ingin bekerja sesuai target dan harapan. Suatu keadaan dalam organisasi di lingkungan sosial perusahaan bisa mengalami kondisi yang berbeda dengan keinginan semua pegawainya. Cara pandang ini dapat menciptakan potensi penolakan maupun penerimaan dari setiap pegawainya. Semakin beragam elemen organisasi yang terlibat dalam sebuah usaha untuk mencapai tujuan dan kepentingan dalam organisasi maka persoalan yang dihadapi akan semakin kompleks. Timbulnya konflik yang terjadi pada individu dan kelompok dalam organisasi dapat disebabkan salah satunya oleh isu keadilan organisasi yang mempengaruhi kepuasan kerja setiap pegawai(Hagemeister \& Volmer, 2018).
Pegawai yang mencapai kepuasan kerja pada umumnya akan menunjukkan sikap dalam bekerja lebih giat. Keterlibatan dan merasa dibutuhkan dalam menyelesaikan pekerjaan menghadirkan kenyamanan bagi pegawai dalam bekerja. Keberhasilan suatu organisasi selain dilihat dari pencapaian kepuasan kerja juga masih didukung oleh pencapaian kualitas kehidupan kerja. Pada hubungan tersebut setiap pegawai dapat mencapai dengan dicirikan sebagai wujud dedikasi pegawai pada pekerjaannya(Bakker, A. B., \& Schaufeli, 2015). Wujud dedikasi pegawai terhadap organisasinya dapat diwujudkan melalui komitmen organisasional. Sehingga kinerja dalam organisasi dapat meningkat pada setiap pegawainya. Kinerja karyawan dapat menjadi arah dalam meningkatkan efisiensi dan produktivitas proses organisasi secara keseluruhan. Mengacu pada kinerja karyawan kegiatan dan tugas pegawai dilaksanakan oleh setiap pegawai. Kinerjanya dapat dilihat melalui kondisi yang dirasakan oleh pegawai yang tidak akan sama(Saleem \& Amin, 2013).

Pada umumnya pegawai tidak mencapai kepuasan kerja sehingga memiliki kualitas kehidupan kerja yang rendah pada perusahaan namun pegawai harus terus mempertahankan konsistensinya dalam bekerja untuk mendorong semangatnya agar tetap berkomitmen dalam organisasi. Perasaan puas yang ditimbulkan dari hasil kerja menjadi salah satu bentuk ungkapan hati setiap pegawai dalam menilai hasil kerjanya. Apabaila pegawai merasa tidak puas terhadap organisasinya dalam bekerja akan 
berpengaruh terhadap perusahaan. Kerugian yang tampak salah satunya terjadi penurunan moral kerja dan terganggunya layanan organisasi internal maupun eksternal. Bentuk pelayanan organisasi yang terganggu dapat ditunjukkan melalui rendahnya semangat kerja sehingga dapat menghambat proses pegawai dalam bekerja(Johari, J., \& Yahya, 2016). Hal tersebut dapat menghadirkan masalah bagi perusahaan jika Manajer tidak memperhatikan kondisi pegawainya.

Penelitian empiris telah dilaksanakan untuk meneliti kepuasan kerja. Seperti (Siengthai \& Pila-Ngarm, 2016) meneliti pada Hotel Resort Industri dan Industri Perbankan di Thailand dengan 295 sampel responden pengelola, hasilnya kepuasan kerja dapat berpengaruh secara langsung terhadap kinerja karyawan. Penelitian(Pawirosumarto, Sarjana, \& Gunawan, 2017) meneliti karyawan Parador Hotel dan Resort Indonesia sebanyak 179 kuesioner yang dianalisis hasilnya kepuasan kerja tidak dapat berpengaruh secara langsung terhadap kinerja karyawan.

Penelitian oleh (Hermawati, Suhermin, \& Puji, 2019) yang meneliti tentang kualitas kehidupan kerja berpengaruh atau tidak terhadap kinerja karyawan pada seluruh karyawan UMKM di PT Malang Raya dan UMKM berkembang di wilayah Jawa Timur dengan sampel 846 karyawan hasilnya kualitas dapat mempengaruhi secara signifian terhadap kinerja karyawan pada semua lokasi penelitian. Oleh penelitian(Asharini, Hardyastuti, \& Irham, 2018) pada karyawan PT. Madubaru PG-PS Maduskismo dengan 100 responden menunjukkan kualitas kehidupan kerja tidak berpengaruh terhadap kinerja karyawan. Inkonsistensi hasil penelitian tersebut merupakan gap research yang akan diuji pada penelitian ini.

Demikian halnya bagi karyawan PT. Ramayana Lestari Sentosa, Tbk cabang Sleman. Penulis mencoba melaksanakan sebuah penelitian mengenai bagaimana pegawai pada PT. Ramayana Lestari Sentosa, Tbk cabang Sleman dapat menjadi karyawan yang berkinerja tinggi serta mengutamakan kepuasan kerja beserta pencapaian kualitas kehidupan kerja untuk dapat menghadapi tantangan dan persaingan bisnis perusahaan secara global. Melalui dukungan Manajer maupun internal perusahaan, penulis membangun sebuah model yang menghubungkan antara kepuasan meliputi kualitas kehidupan kerja yang berpengaruh dengan kinerja karyawan menggunakan mediasi komitmen organisasional.

\section{TINJAUAN PUSTAKA}

\section{Kepuasan Kerja}

Kepuasan kerja mengarah pada kondisi ketika setiap karyawan secara emosional dapat menikmati hasil pekerjaan dan kinerjanya(Shaikh, 2012). Kepuasan kerja juga dapat diukur sebagai wujud kesejahteraan yang dicapai oleh setiap karyawan. Jika karyawan tidak sejahtera dalam bekerja akan tercermin pada kinerjanya yang rendah. Kepuasan kerja dapat muncul kepada setiap karyawan yang menyesuaikan kebutuhan karyawan yang berbeda. Kebutuhan tidak hanya dalam bentuk materi (gaji) akan 
tetapi juga termasuk non materi seperti prestasi, jabatan, kesempatan mengembangkan diri, dan sosial. Kebutuhan materi maupun non materi dapat dipenuhi melalui cara dan proses selama bekerja dengan kemampuan yang dapat memberikan manfaat bagi tempat karyawan bekerja. Pada saat bekerja umumnya setiap karyawan mulai mempunyai harapan untuk mencukupi suatu kebutuhan. Kepuasan kerja tidak tercapai biasanya muncul pada saat seorang karyawan memiliki sebuah harapan terhadap organisasinya namun tidak terwujud. Hal tersebut merupakan perbandingan antara kontribusi dan imbalan yang diterimanya tidak sesuai dengan yang diharapkan. Kepuasan kerja dapat terjadi pada saat imbalan yang diterima karyawan tidak seperti harapan terhadap kerja yang dilakukan seorang karyawan terhadap organisasinya. Setiap karyawan dalam bekerja mampu melibatkan dirinya serta lingkungan kerjanya untuk mempengaruhi hasil dari proses karyawan dalam bekerja. Proses karyawan dalam bekerja dapat mendorong karyawan guna memaksimalkan kemampuan kerjanya sehingga dapat berkontribusi terhadap organisanya. Secara umum kepuasan kerja diukur melalui reaksi yang diterima oleh setiap karyawan di tempat kerja(Khalilzadeh, Chiappa, Jafari, \& Borujeni, 2013).
2. Kualitas Kehidupan Kerja

Kualitas Kehidupan Kerja memiliki hubungan dari serangkaian tujuan, kondisi, dan praktik organisasi yang mencerminkan karyawan mencapai kepuasan dalam bekerja dan memiliki peluang untuk tumbuh dan mengembangkan kemampuannya dalam bekerja(S. Ahmad, 2013). Suatu organisasi akan menawarkan kualitas kehidupan kerja kepada karyawan sebagai bentuk citra perusahaan kepada karyawannya. Pada umumnya menumbuhkan kualitas kehidupan kerja sebagai wujud rasa ingin bertahan untuk tetap bekerja dan bergabung dalam organisasinya. Hal tersebut menunjukkan rasa puas bekerja terhadap organisasi. Bekerja dapat dinilai melalui kepuasan kerja dari bentuk apresiasi yang telah diberikan perusahaan kepada setiap karyawan. Kehidupan karyawan di tempat kerja dapat didukung oleh kondisi kualitas kehidupan kerja melalui tingkat kepuasan kerja karyawan, motivasi dan keterlibatan karyawan terhadap suatu pekerjaan dan komitmen karyawa terhadap organisasinya. Perusahaan pada umumnya meningkatkan kualitas kehidupan kerja dengan memberikan perasaan aman, rasa memiliki, tanggung jawab dan fleksibilitas kepada karyawan. Sebagai wujud perusahaan dalam memberikan rasa keadilan, terbuka, dan memberikan kesempatan pada karyawan untuk berpartisipasi dalam diskusi terkait suatu keputusan organisasi(Srivastava \& 
Kanpur, 2014).

\section{Komitmen Organisasional}

Komitmen Organisasional merupakan salah satu dari wujud komitmen yang dimiliki individu dari dalam dan luar pekerjaannya(Klein, Molloy, \& Brinsfield, 2012). Karyawan yang berkomitmen pada umumnya akan mendedikasikan diri lebih banyak waktu dan usaha untuk bekerja. Selain itu karyawan dapat bersama mendukung dan mencapai target perusahaan yang bernilai serta memiliki tujuan sebagai wujud karyawan yang berkomitmen. Peran dari komitmen organisasional dapat menjadi faktor untuk membangun komitmen bagi karyawan yang memiliki kinerja yang tinggi. Peran dari komitmen organisasional adalah semakin tinggi komitmen maka akan semakin tinggi kinerja karyawannya(Zincirkiran, Emhan, \& Fatih Yasar, 2015). Hubungan antara praktik oleh sumber daya manusia(karyawan) dengan kinerja organisasi dapat diperkuat dengan adanya komitmen organisasi(Supriyanto \& Maharani, 2015). Pada umumnya persepsi dari rekan kerja dapat mempengaruhi komitmen organisasi. Hal tersebut didukung oleh bagaimana hubungan kerja antar pegawai. Jika karyawan dapat mencapai konsistensi bekerja untuk memiliki motivasi yang menghasilkan kinerja terbaik. Sehingga mendorong karyawan untuk tetap mempertahankan keanggotannya pada sebuah organisasi karena secara emosional merasa terikat antara hubungan karyawan dan organisasinya. Manfaat yang diberikan oleh organisasi kepada karyawan salah satunya dapat menjadi alasan karyawan berkomitmen pada organisasinya.

\section{Kinerja Karyawan}

Kinerja dapat diartikan sebagai tindakan kerja yang mengubah kinerja dari abstraksi menjadi hasil dan mengelola kinerja tim menjadi hasil dari suatu pekerjaan(I. Dugguh \& Dennis, 2014). Kinerja karyawan sebagai wujud aktivitas mengenai suatu pekerjaan yang diharapkan dari setiap karyawan dan bagaimana karyawan tersebut akan menjalankannya. Kinerja karyawan melibatkan kualitas dan kuantitas dari suatu pekerjaan yang sudah dikerjakan oleh karyawan(Shahzadi, Javed, Pirzada, Nasreen, \& Khanam, 2014). Jika karyawan merasa puas pada kondisi organisasinya maka karyawan akan melakukan lebih banyak pekerjaan untuk organisasinya(M. B. Ahmad, Wasay, \& Malik, 2012). Motivasi dapat mempengaruhi kepuasan kerja sehingga setiap karyawan jika merasa termotivasi maka akan lebih banyak usaha untuk melaksanakan pekerjaannya(Azar \& Shafighi, 2013). Pemberian pelatihan karyawan salah satunya dapat menumbuhkan kinerja yang mengarah pada peningkatan dalam performa kerja. Meningkatkan dan memperbarui kemampuan serta pengetahuan karyawan melalui pelatihan dapat meningkatkan kompetensi karyawan. Jika setiap 
karyawan berkompeten maka kinerja dapat meningkat dan perusahaan mencapai keuntungan sehingga bermanfaat untuk jangka panjang(Ameeq-ul-Ameeq \& Hanif, 2013).

\section{METODE PENELITIAN}

\section{Populasi}

Dalam penelitian ini responden berasal dari 80 karyawan PT. Ramayana Lestari Sentosa,Tbk Cabang Sleman.

\section{Sampel}

Penelitian ini menggunakan teknik pengambilan sampling dengan sampel jenuh. Semua populasi responden sejumlah 80 karyawan dijadikan sebagai sampel.

\section{Jenis Penelitian}

Jenis penelitian ini bersifat deskriptif kuantitatif yang bertujuan mendeskripsikan data yang terkumpul dalam wujud angka dengan menggunakan statistik. Penelitian ini menjadi penelitian dasar (pure research) untuk menemukan suatu generalisasi atau teori tertentu.

\section{Metode Analisis Data}

Metode analisis data dengan uji instrumen, uji asumsi klasik, uji hipotesis, dan sobel test.

\section{HASIL PENELITIAN}

\section{Uji Instrumen}

Uji validitas untuk mengukur konsistensi butir pertanyaan dan dapat mencerminkan indikator yang akan diteliti untuk mengukur validitas kuesioner dilakukan melalui cara menghitung korelasi antara skor masing-masing item pertanyaan dengan total skor pada konstruknya. Uji signifikansi melalui cara membandingkan $r$ hitung dengan $r$ tabel ( $r$ hitung $>r$ tabel) sehingga akan ditemukan butir pertanyaan yang dapat dinyatakan valid atau tidak valid. Menguji derajat kebebasan $\mathrm{df}=\mathrm{N}$ $2(\mathrm{df}=80-2=78)$ diperoleh $\mathrm{r}$ tabel sebesar 0,2199 melalui uji dua arah. Pada butir pernyataan valid mempunyai $r$ hitung lebih besar dari $r$ tabel ( $r$ hitung $>r$ tabel) $(0,2199)$ sehingga pada instrumen penelitian ini semua butir pertanyaan dapat dinyatakan layak sebagai instrumen untuk mengukur data penelitian.

Selanjutnya pada uji reliabilitas menghasilkan dapat dilihat pada tabel 1 pengujian bertujuan untuk mengetahui seberapa jauh alat ukur dapat dipercaya sehingga menunjukkan keandalan sebuah alat ukur. Kalkulasi koefisien alpha menggunakan bantuan SPSS. Dalam pengujian ini dilakukan dengan uji Cronbach's Alpha Based on Standardized Items, dengan nilai Cronbach's Alpha Based > 0,60 didapat instrumen tersebut dikatakan handal atau reliabel. Berpedoman (Ghozali, 2006) mengenai butir pernyataan yang valid dalam kuesioner penelitian dinyatakan reliabel berarti kuesioner memiliki hasil yang konsisten jika dilakukan pengukuran dalam waktu dan model atau desain yang berbeda. Variabel kepuasan kerja (X1), variabel kualitas kehodupan kerja (X2), variabel komitmen organisasional (Y) dan variabel mediasi yaitu komitmen organisasional (Z) menghasilkan Cronbach's Alpha lebih besar dari 
0.60 dapat dinyatakan reliabel.

Tabel 1. Hasil Uji Reliabilitas

\begin{tabular}{l|l|l|l}
\multicolumn{1}{c}{ Variabel } & Cronbach's Alpha & Nilai Kritis Alpha & Keterangan \\
\hline Kepuasan Kerja & 0.627 & 0.60 & Reliabel \\
\hline Kualitas Kehidupan Kerja & 0.968 & 0.60 & Reliabel \\
Komitmen Organisasional & 0.848 & 0.60 & Reliabel \\
Kinerja Karyawan & 0.744 & 0.60 & Reliabel \\
\hline
\end{tabular}

Sumber : Data Primer, diolah, 2021

\section{Uji Asumsi Klasik}

Uji normalitas pada penelitian ini dilakukan dengan statistik yaitu uji KolmogorovSmirnov (KS), melalui nilai signifikansinya. Data berdistribusi normal jika nilai signifikansinya > 0,05 . Dilihat dari gambar uji Kolmogorov-Smirnov dapat

Tabel 2. Hasil Normalitas Kolmogorov-Smirnov Test of Normality

One-Sample Kolmogorov-Smirnov Test

Unstandardized Residual

\begin{tabular}{ll}
\hline Kolmogorov-Smirnov Z & .640 \\
Asymp. Sig. (2-tailed) & .807 \\
\hline
\end{tabular}

a. Test distribution is Normal.

b. Calculated from data.

One-Sample Kolmogorov-Smirnov Test

\begin{tabular}{l|c} 
& Unstandardized Residual \\
\hline Kolmogorov-Smirnov Z & .426 \\
Asymp. Sig. (2-tailed) & .994 \\
\hline
\end{tabular}

a. Test distribution is Normal.

b. Calculated from data.

Sumber : Data Primer, diolah, 2021

\section{Uji Multikolinearitas}

Uji multikolinearitas dapat membuktikan variabel bebas tidak terjadi pengaruh korelasi antar variabel yang ditentukan sebagai model penelitian. Uji multikolinearitas bertujuan guna memastikan nilai Tolerance $>0.10$ dan $V I F<10$ artinya tidak terjadi multikolinearitas. Sehingga pada variabel kepuasan kerja dan kualitas kehidupan kerja terhadap komitmen organisasional menghasilkan nilai Tolerance sebesar 0.946 lebih besar dari 0.10 dengan nilai VIF sebesar 1.057 kurang dari 10 . Artinya tidak terjadi multikolinearitas. Pada variabel selanjutnya kepuasan kerja, kualitas kehidupan kerja dan komitmen organisasional terhadap kinerja karyawan menghasilkan nilai Tolerance lebih besar dari 0.10 dan nilai VIF kurang dari 10 . Sehingga semua variabel pada penelitian ini tidak terjadi 
multikolinearitas.

Tabel 3. Hasil Uji Multikolinearitas dengan Collinearity Statistics Coefficients ${ }^{\mathrm{a}}$

\begin{tabular}{|c|c|c|c|c|c|c|}
\hline \multirow[t]{2}{*}{ Model } & \multicolumn{2}{|c|}{$\begin{array}{l}\text { Unstandardized } \\
\text { Coefficients }\end{array}$} & \multirow{2}{*}{$\begin{array}{c}\text { Standardize } \\
\mathrm{d} \\
\text { Coefficients } \\
\text { Beta }\end{array}$} & \multirow[t]{2}{*}{$\mathrm{t}$} & \multicolumn{2}{|c|}{$\begin{array}{l}\text { Collinearity } \\
\text { Statistics }\end{array}$} \\
\hline & B & $\begin{array}{l}\text { Std. } \\
\text { Error }\end{array}$ & & & $\begin{array}{c}\text { Toleranc } \\
\mathrm{e}\end{array}$ & VIF \\
\hline (Constant) & 17.598 & 8.445 & & 2.084 & & \\
\hline Kepuasan Kerja & .699 & .180 & .344 & 3.879 & .946 & 1.057 \\
\hline $\begin{array}{l}\text { Kualitas Kehidupan } \\
\text { Kerja }\end{array}$ & .190 & .035 & .482 & 5.433 & .946 & 1.057 \\
\hline
\end{tabular}

a. Dependent Variable: Komitmen Organisasional

\begin{tabular}{|c|c|c|c|c|c|c|c|}
\hline \multirow{3}{*}{\multicolumn{2}{|c|}{ Model }} & \multicolumn{4}{|c|}{ Coefficients $^{\mathrm{a}}$} & \multirow{2}{*}{\multicolumn{2}{|c|}{ Collinearity Statistics }} \\
\hline & & \multicolumn{2}{|c|}{$\begin{array}{l}\text { Unstandardize } \\
\text { d Coefficients }\end{array}$} & \multirow{2}{*}{$\begin{array}{l}\text { Standardiz } \\
\text { ed } \\
\text { Coefficien } \\
\text { ts } \\
\text { Beta }\end{array}$} & \multirow[t]{2}{*}{$\mathrm{t}$} & & \\
\hline & & $\mathrm{B}$ & $\begin{array}{l}\text { Std. } \\
\text { Error }\end{array}$ & & & $\begin{array}{c}\text { Toleran } \\
\text { ce }\end{array}$ & \multirow[t]{2}{*}{ VIF } \\
\hline \multirow{4}{*}{1} & (Constant) & 4.238 & 3.441 & & 1.232 & & \\
\hline & Kepuasan Kerja & .146 & .078 & .137 & 1.871 & .792 & 1.263 \\
\hline & $\begin{array}{l}\text { Kualitas Kehidupan } \\
\text { Kerja }\end{array}$ & .054 & .016 & .264 & 3.340 & .684 & 1.462 \\
\hline & $\begin{array}{l}\text { Komitmen } \\
\text { Organisasional }\end{array}$ & .301 & .045 & .574 & 6.659 & .573 & 1.746 \\
\hline
\end{tabular}

a. Dependent Variable: Kinerja Karyawan

Sumber : Data Primer, diolah, 2021

\section{c. Uji Heteroskedastisitas}

Penelitian ini menggunakan uji statistik dilakukan menggunakan uji glejser dengan nilai probabilitas signifikansi > heteroskedastisitas dinyatakan bahwa nilai signifikansi variabel diatas 0.05. Semua variabel konsisten tidak terjadi gejala heteroskedastisitas.
0.05 .
Uji
statistik

Tabel 4. Hasil Uji Glejser Statistik Heteroskedastisitas

\section{Coefficients ${ }^{\mathrm{a}}$}

Model

\begin{tabular}{l|l|l|l} 
Unstandardized & Standardize & $\mathrm{t}$ & Sig.
\end{tabular} Coefficients

B $\quad$ Std.

Error

Coefficient

\begin{tabular}{|c|c|c|c|c|c|}
\hline & & & Beta & & \\
\hline (Constant) & .580 & 1.938 & & .299 & .766 \\
\hline Kepuasan Kerja & -.038 & .044 & -.111 & -.876 & .384 \\
\hline $\begin{array}{l}1 \text { Kualitas } \\
\text { Kehidupan Kerja }\end{array}$ & -.003 & .009 & -.047 & -.347 & .729 \\
\hline $\begin{array}{l}\text { Komitmen } \\
\text { Organisasional }\end{array}$ & .041 & .025 & .242 & 1.631 & .107 \\
\hline
\end{tabular}

a. Dependent Variable: ABS_RES2 


\begin{tabular}{|c|c|c|c|c|c|}
\hline \multirow{3}{*}{ Model } & \multicolumn{3}{|c|}{ Coefficients ${ }^{a}$} & \multirow{3}{*}{$\mathrm{t}$} & \multirow{3}{*}{ Sig. } \\
\hline & \multicolumn{2}{|c|}{$\begin{array}{l}\text { Unstandardized } \\
\text { Coefficients }\end{array}$} & \multirow{2}{*}{$\begin{array}{c}\text { Standardiz } \\
\text { ed } \\
\text { Coefficien } \\
\text { ts } \\
\text { Beta } \\
\end{array}$} & & \\
\hline & $\mathrm{B}$ & Std. Error & & & \\
\hline (Constant) & -.024 & .058 & & -.413 & .681 \\
\hline Kepuasan Kerja & .001 & .001 & .060 & .521 & .604 \\
\hline $\begin{array}{l}\text { Kualitas } \\
\text { Kehidupan Kerja }\end{array}$ & .000 & .000 & .149 & 1.294 & .200 \\
\hline
\end{tabular}

a. Dependent Variable: ABS_RES3

Sumber : Data Primer, diolah, 2021

\section{Uji Hipotesis}

Tabel 5 menunjukkan hasil pengujian $\mathrm{H} 1$ diterima dengan nilai sig. $<0.05, \mathrm{H} 2$ diterima nilai sig. $<0.05$. Besarnya kepuasan kerja dan kualitas kehidupan kerja yang berpengaruh terhadap komitmen organisasional sebesar 41.2\%. H3 diterima dengan sig.< 0.05 . Besarnya pengaruh kepuasan kerja, kualitas kehidupan kerja, dan komitmen organisasional dapat mempengaruhi kinerja karyawan sejumlah $66.4 \%$.

\section{Tabel 5. Hasil Uji Hipotesis}

Coefficients

\begin{tabular}{|c|c|c|c|c|c|c|}
\hline \multirow{2}{*}{\multicolumn{2}{|c|}{ Model }} & \multicolumn{2}{|c|}{$\begin{array}{l}\text { Unstandardized } \\
\text { Coefficients }\end{array}$} & \multirow{2}{*}{$\begin{array}{c}\text { Standardized } \\
\text { Coefficients } \\
\text { Beta }\end{array}$} & \multirow[t]{2}{*}{$\mathrm{t}$} & \multirow[t]{2}{*}{ Sig. } \\
\hline & & B & $\begin{array}{l}\text { Std. } \\
\text { Error }\end{array}$ & & & \\
\hline \multirow{5}{*}{1} & (Constant) & 17.598 & 8.445 & & 2.084 & .040 \\
\hline & Kepuasan & 699 & 180 & 344 & 3.879 & .000 \\
\hline & Kerja & & & & & \\
\hline & Kualitas & & & & & \\
\hline & $\begin{array}{l}\text { Kehidupan } \\
\text { Kerja }\end{array}$ & .190 & .035 & .482 & 5.433 & .000 \\
\hline
\end{tabular}

a. Dependent Variable: Komitmen Organisasional

Model

Coefficients $^{\mathrm{a}}$

\begin{tabular}{|c|c|c|c|c|c|c|}
\hline \multirow{2}{*}{\multicolumn{2}{|c|}{ Model }} & \multicolumn{2}{|c|}{$\begin{array}{l}\text { Unstandardized } \\
\text { Coefficients }\end{array}$} & \multirow{2}{*}{$\begin{array}{c}\text { Standardized } \\
\text { Coefficients } \\
\text { Beta }\end{array}$} & \multirow[t]{2}{*}{$\mathrm{t}$} & \multirow[t]{2}{*}{ Sig. } \\
\hline & & B & $\begin{array}{l}\text { Std. } \\
\text { Error }\end{array}$ & & & \\
\hline \multirow{4}{*}{1} & (Constant) & 4.238 & 3.441 & & 1.232 & .222 \\
\hline & $\begin{array}{l}\text { Kepuasan } \\
\text { Kerja }\end{array}$ & .146 & .078 & .137 & 1.871 & .065 \\
\hline & $\begin{array}{l}\text { Kualitas } \\
\text { Kehidupan } \\
\text { Kerja }\end{array}$ & .054 & .016 & .264 & 3.340 & .000 \\
\hline & $\begin{array}{l}\text { Komitmen } \\
\text { Organisasional }\end{array}$ & .301 & .045 & .574 & 6.659 & .000 \\
\hline
\end{tabular}

a. Dependent Variable: Kinerja Karyawan

Sumber : Data Primer, diolah, 2021 


\section{UJI SOBEL TEST}

Hasil perhitungan Sobel test (Gambar 1) menunjukkan nilai two tailed probability sebesar 0.0 dengan tingkat signifikansi 5\% dari hasil tersebut dapat disimpulkan bahwa
$0.0<0,05$ yang membuktikan bahwa variabel komitmen organisasional memediasi pengaruh kepuasan kerja terhadap kinerja karyawan.

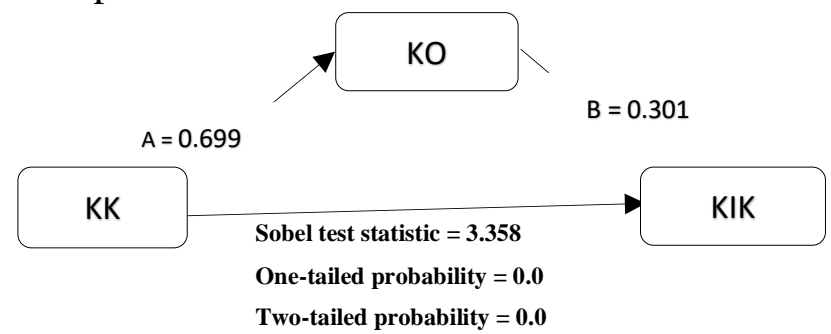

Sumber : Data Primer, diolah, 2021

Gambar 1. Mediasi Hipotesis 4

Mediasi Hipotesis 4 karyawan mampu dimediasi oleh menghasilkan uji sobel test (Gambar komitmen organisasional, namun 1) menunjukkan nilai two tailed kepuasan kerja tidak dapat probability 0.0 meliputi tingkat berpengaruh secara langsung signifikansi $5 \%$ dari hasil tersebut terhadap kinerja karyawan. dapat disimpulkan bahwa $0.0<0,05$ yang membuktikan bahwa variabel kepuasan kerja terhadap kinerja

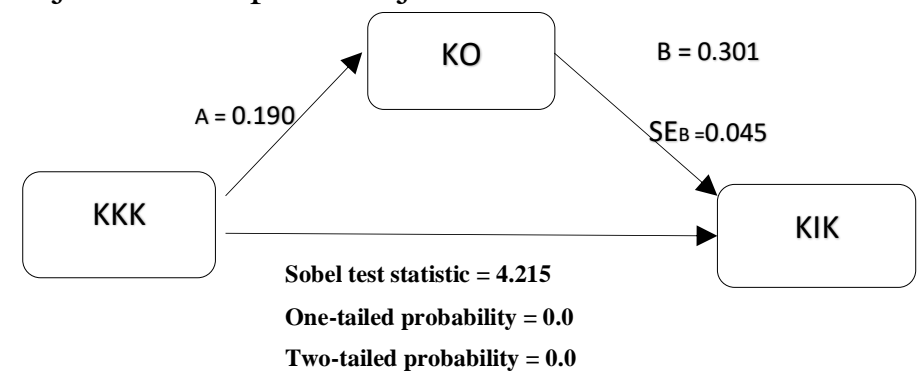

Sumber : Data Primer, diolah, 2021

Gambar 2. Mediasi Hipotesis

Hasil perhitungan Sobel test (Gambar 2) menunjukkan nilai two tailed probability sebesar 0.0 dengan tingkat signifikansi 5\% dari hasil tersebut dapat disimpulkan bahwa $0.0<0,05$ yang membuktikan bahwa variabel komitmen organisasional memediasi pengaruh kualitas kehidupan kerja terhadap kinerja karyawan.
PEMBAHASAN

\section{Pengaruh Kepuasan Kerja Terhadap Komitmen Organisasional}

Kepuasan Kerja memiliki t hitung sebesar 3.879 dan signifikansi 0.00 . Maka dapat disimpulkan bahwa $\mathrm{t}$ tabel $<\mathrm{t}$ hitung $(1.991<3.879)$ dan signifikansi $0.00<0.05$ karena 
dalam pengujian ini menggunakan dua arah, maka hipotesis $1 \mathrm{Ha}$ diterima. Kepuasan kerja karyawan dalam bekerja terbukti dapat meningkatkan komitmen organisasional. Jadi semakin besar karyawan dapat mencapai kepuasan kerjanya maka semakin tinggi rasa komitmen organisasional yang timbul pada diri karyawan.

2. Pengaruh Kualitas Kehidupan Kerja Terhadap Komitmen Organisasional

Kualitas kehidupan kerja memiliki t hitung sebesar 5.433 dan signifikansi 0.00. Maka dapat disimpulkan bahwa $\mathrm{t}$ tabel $<\mathrm{t}$ hitung $(1.991<5.433)$ dan signifikansi $0.00<0.05$ karena dalam pengujian ini menggunakan dua arah, maka hipotesis $2 \mathrm{Ha}$ diterima. Jika suatu perusahaan mampu memberikan kualitas kehidupan kerja kepada karyawan dengan memuaskan maka dapat mempengaruhi peningkatan komitmen dari dalam diri karyawan terhadap organisasinya. Sehingga untuk menghadapi persaingan industri yang semakin pesat perusahaan harus membekali karyawan dengan pencapaian kualitas kehidupan kerja sehingga terdorong untuk memiliki keterikatan dari setiap karyawan kepada organisasinya dan merasa tidak ingin meninggalkan(resign) dari organisasinya.

3. Pengaruh

Organisasional Kinerja Karyawan

Komitmen organisasional memiliki t hitung sebesar 6.659 dan signifikansi 0.00. Maka dapat disimpulkan bahwa $\mathrm{t}$ tabel $<\mathrm{t}$ hitung dengan $(6.659<5.433)$ dan signifikansi $0.00<0.05$ karena dalam pengujian ini menggunakan dua arah, maka hipotesis $3 \mathrm{Ha}$ diterima. Karyawan yang berkomitmen terhadap organisasinya dapat menumbuhkan kesadaran pada dirinya agar lebih semangat dalam bekerja sehingga memiliki kinerja yang tinggi. Kinerja karyawan yang tinggi dapat menjadi cerminan bagi sebuah organisasi yang berhasil memberikan kenyamanan kepada karyawannya dalam bekerja

4. Peran Mediasi Komitmen Organisasional Terahdap Kepuasan Kerja Terhadap Kinerja Karyawan

Kepuasan kerja memiliki t hitung sebesar 1.871 dan signifikansi 0.065 . Maka dapat disimpulkan bahwa $\mathrm{t}$ tabel $<\mathrm{t}$ hitung dengan $(1.871<5.433)$ dan signifikansi $0.065>0.05$. Sehingga variabel kepuasan kerja terhadap kinerja karyawan tidak dapat berpengaruh secara langsung, sehingga pengaruh kepuasan kerja terhadap kinerja karyawan dapat dimediasi oleh komitmen organisasonal. Hal tersebut mengartikan bahwa komitmen organisasional dapat meningkat jika dipengaruhi oleh pencapaian kepuasan kerja serta dapat meningkatkan kinerja karyawan.

5. Peran Mediasi Komitmen Organisasional Terhadap Kualitas Kehidupan Kerja Terhadap Kinerja Karyawan

Kepuasan kerja memiliki t hitung sebesar 3.340 dan signifikansi 0.00 . Maka dapat 
disimpulkan bahwa $\mathrm{t}$ tabel $<\mathrm{t}$ hitung dengan $(3.340<5.433)$ dan signifikansi $0.00>0.05$. Artinya komitmen organisasional mampu memediasi kinerja karyawan yang dipengaruhi oleh kualitas kehidupan kerja. Serta kualitas kehidupan kerja dapat berpengaruh secara langsung terhadap kinerja karyawan. Semakin kuat karyawan dalam berkomitmen terhadap organisasinya seperti salah satunya karyawan mendapatkan kompensasi yang layak dan adil dapat mendorong karyawan merasa nyaman terhadap organisasinya sehingga karyawan dapat mencapai kualitas kehidupan kerja yang baik serta berpengaruh terhadap peningkatan kinerja karyawan.

\section{KESIMPULAN DAN SARAN}

Penelitian menghasilkan temuan pada variabel kinerja karyawan yang tidak dapat dipengaruhi secara langsung oleh kepuasan kerja namun dapat dimediasi oleh komitmen organisasional. Perusahaan diharapkan dapat meningkatkan dan mempertahankan karyawan dalam mencapai kepuasan kerja sehari-hari, sehingga karyawan dapat yakin berkomitmen kepada organisasinya yang terbukti dapat meningkatkan kinerja karyawan.

Untuk membekali karyawan agar dapat berkomitmen terhadap Perusahaan Manajer dapat melaksanakan salah satunya memberikan kesempatan bagi karyawan turut serta dalam berbagai kesempatan kerja, kesempatan untuk terlibat dalam pengambilan keputusan, dan menjalin kedekatan kepada semua karyawan secara langsung untuk berdiskusi mengenai kondisi kerja. Sehingga karyawan dapat berkomitmen terhadap perusahaan dan meningkatkan kinerjanya. Temuan selanjutnya menunjukkan komitmen organisasional dapat memediasi pengaruh kualitas kehidupan kerja secara langsung terhadap kinerja karyawan.

Sebagai implikasinya, perusahaan salah satunya dapat membagikan kompensasi yang layak dan adil kepada semua karyawan, memberikan kesempatan bagi karyawan untuk berkembang dan meningkatkan kapasitas diri seperti menyelenggarakan pelatihan bagi karyawan, melalui pelatihan guna pengembangan kapasitas diri sehingga dapat memperkuat pengaruh kualitas kehidupan kerja yang konsekuensinya akan meningkatkan komitmen organisasional yang mendorong karyawan berkinerja secara optimal.

\section{DAFTAR PUSTAKA}

Ahmad, M. B.,et al.(2012). I Nterdisciplinary J Ournal O F C Ontemporary R Esearch I N B Usiness Impact of Employee Motivation on Customer Satisfaction: Study of Airline Industry in Pakistan. Interdisciplinary Journal of Contemporary Research in Business, 04(06), 531-539. Retrieved from http://papers.ssrn.com/sol3/pape rs.cfm?abstract_id=2183591

Ahmad, S. (2013). Paradigms of quality of work life. Journal of Human Values, 19(1), 73-82. 
doi:10.1177/097168581247034 5

Ameeq-ul-Ameeq, \& Hanif, F. (2013). Impact of Training on $\mathrm{E}$ mployee' s Development and Performance in Hotel Industry of Lahore , Pakistan. Journal of Business Studies Quarterly, 4(4), 68-83. Retrieved from http://jbsq.org/wpcontent/uploads/2013/06/June_2 013_5.pdf

Asharini, N. A., et al.(2018). The Impact of Quality of Work Life and Job Satisfaction on Employee Performance of PT. Madubaru PG-PS Madukismo. Agro Ekonomi, 29(1), 146. doi:10.22146/ae.31491

Azar, M., \& Shafighi, A. A. (2013). The Effect of Work Motivation on $\quad$ Employeesâ $\square$ TM Job Performance (Case Study: Employees of Isfahan Islamic Revolution Housing Foundation). International Journal of Academic Research in Business and Social Sciences, 3(9), 432-445. doi:10.6007/ijarbss/v3-i9/231

Bakker, A. B., \& Schaufeli, W. B. (2015). Work engagement. Organizational Psychology and Evidence-Based Management: What Science Says about Practice, (2008), 63-80. doi:10.1007/978-3-319-64304$5 \_4$

Ghozali, Imam. 2006. Aplikasi Analisis Multivariate dengan Program SPSS (Edisi Keempat). Semarang:Badan Penerbit Universitas Diponegoro

Güngör, P. (2011). The relationship between reward management system and employee performance with the mediating role of motivation: A quantitative study on global banks. Procedia - Social and Behavioral Sciences, 24, 15101520.

doi:10.1016/j.sbspro.2011.09.02 9

Hagemeister, A., \& Volmer, J. (2018). Do social conflicts at work affect employees' job satisfaction?: The moderating role of emotion regulation. International Journal of Conflict Management, 29(2), 213-235. doi:10.1108/IJCMA-11-20160097

Hermawati, A., Suhermin, \& Puji, R. (2019). The transglobal leadership-based strategy of MSMEs performance optimization of Malang Raya and the implementation of quality of work life. Research Journal of Textile and Apparel, 23(1), 38-57. doi:10.1108/RJTA-05-20180038

I. Dugguh, S., \& Dennis, A. (2014). Job satisfaction theories: Traceability to employee performance in organizations. IOSR Journal of Business and Management, 16(5), 11-18. doi:10.9790/487x-16511118

Johari, J., \& Yahya, K. K. (2016). European Journal of Training and Development. European Journal of Training and Development European Journal of Training and Development Iss European Journal of Training and Development (Vol. 40). Retrieved from http://dx.doi.org/10.1108/EJTD02-2016-0008 
Johnson, R. E., et al.(2010). Commitment and motivation at work: The relevance of employee identity and regulatory focus. Academy of Management Review, 35(2), 226-245. doi:10.5465/AMR.2010.484633 32

Khalilzadeh, J., et al.(2013). Methodological approaches to job satisfaction measurement in hospitality firms. International Journal of Contemporary Hospitality Management, 25(6), 865-882. doi:10.1108/IJCHM05-2012-0067

Klein, H. J., et al.(2012). Reconceptualizing workplace commitment to redress a stretched construct: Revisiting assumptions and removing confounds. Academy of Management Review, 37(1), 130-151. doi:10.5465/amr.2010.0018

Koonmee, K., et al.(2010). Ethics institutionalization, quality of work life, and employee jobrelated outcomes: A survey of human resource managers in Thailand. Journal of Business Research, 63(1), 20-26. doi:10.1016/j.jbusres.2009.01.0 06

Pawirosumarto, S., et al.(2017). The effect of work environment, leadership style, and organizational culture towards job satisfaction and its implication towards employee performance in Parador hotels and resorts, Indonesia. International Journal of Law and Management, 59(6), 1337-
1358. doi:10.1108/IJLMA-102016-0085

Pulakos, E. D. (2004). Performance Management: A Roadmap for Developing Implementing and Evaluating Performance Management Systems. South Asian Journal of Management, 150.

Rozi, A., \& Puspitasari, A. (2021). Pengaruh Pengembangan Karir Dan Pelatihan Kerja Terhadap Kinerja Pegawai Pada Dinas Perhubungan Kota Serang. JENIUS (Jurnal Ilmiah Manajemen Sumber Daya Manusia), 4(2), 106-119.

Saleem, S., \& Amin, S. (2013). The Impact of Organizational Support for Career Development and Supervisory Support on Employee Performance: An Empirical Study from Pakistani Academic Sector. European Journal of Business and Management, 5(5), 194-207.

Shahzadi, I., et al.(2014). Impact of Employee Motivation on Employee Performance. European Journal of Business and ManagementOnline), 6(23), 2222-2839.

Shaikh, M. A. (2012). Facets of Job Satisfaction and Its Association with Performance. International Journal of Business and Social Science, 3(7), 322-326.

Siengthai, S., \& Pila-Ngarm, P. (2016). The interaction effect of job redesign and job satisfaction on employee performance. Evidence-Based HRM, 4(2), 162-180. doi:10.1108/EBHRM01-2015-0001

Srivastava, S., \& Kanpur, R. (2014). A Study On Quality Of Work 
Life: Key Elements \& It's Implications. IOSR Journal of Business and Management, 16(3), 54-59. doi:10.9790/487x16315459

Supriyanto, A., \& Maharani, V. (2015). Relationship between Human Resource Management (HRM) Practices and Organizational Performance Moderated by Organizational Commitment. Australian Journal of Basic and Applied Sciences, 9(7), 185-188.
Umar, N., et al.(2011). Office harassment: A negative influence on quality of work life. African Journal of Business Management, 5(25), 1027610285. doi:10.5897/ajbm11.766

Zincirkiran, M., et al.(2015). Analysis of Teamwork, Organizational Commitment and Organizational Performance: A Study of Health Sector in Turkey. Asian Journal of Business and Management, 03(02), 2321-2802. Retrieved from www.ajouronline.com 